\title{
Federalismo y regionalismo en Europa: ¿hacia qué camino político camina la UE?
}

\author{
Federalism and Regionalism in Europe: \\ Which Political Road for the EU?
}

\author{
Igor Filibi \\ Profesor de Relaciones Internacionales, Universidad del País Vasco(UPV/EHU) \\ Email: igor.filibi@ehu.eus
}

Sumario: I. Introducción.-II. Procesos de periferialización. 1. Periferialización de Europa y procesos de integración. 2. Periferialización de los Estados e integración sub-regional. 3. Periferialización de las regiones. 3.1. Periferialización dentro del Estado. 3.2. Periferialización dentro de la UE.III. Respuestas a los procesos de periferialización. 1. Federalismo. 2. Subregionalismo. 3. Regionalismo y regionalización.-IV. Reflexiones finales

Resumen: En este artículo se sostiene que el camino político de la integración europea pasa, entre otras cuestiones, por desarrollar la integración de subregiones europeas (Consejo Nórdico, Consejo Báltico, Visegràd, etc.) que completen el proceso central de integración, y por incorporar plenamente a las regiones constitucionales a los procesos de toma de decisiones de la Unión, particularmente al puñado de regiones que tienen una conciencia nacional distintiva, amplias competencias legislativas y mayorías políticas distintas de las del Estado del que forman parte. Estos desarrollos parece que podrían jugar un papel importante, tanto para conseguir una gobernanza de la UE más eficaz, como para que la UE mejore su legitimidad.

Palabras clave: Federalismo europeo, Unión Europea, Regiones, Regionalismo, Regionalización

Abstract: This article shows how the political road of the EU implies, among some other issues, to develop the integration of European sub-regions (Nordic Council, Baltic Council, Visegràd, etc.) completing the overall integration process, and to incorporate fully the regions to the Union's decision-making procedures; particularly, the handful of regions with their own national consciousness, wide legislative powers and political majorities different from the State's ones. These developments are likely to play an important role for improving the effectiveness of the EU governance and its legitimacy.

Keywords: European Federalism, European Union, Regions, Regionalism, Regionalization 


\section{Introducción}

Si se abandona por un momento la mirada estatocéntrica, en la actualidad, de las treinta principales economías del mundo, doce son subestatales. Esta tendencia se produce simultáneamente con la urbanización global del planeta: la mitad de la población mundial se concentra en apenas el $2 \%$ de la superficie de la Tierra, y este $2 \%$ del territorio genera el $80 \%$ de la economía mundial. ONU-Habitat estima que en 2050 las personas que viven en ciudades serán el 75\%, y según esta agencia el siglo que transcurre entre 1950 y 2050 será recordado como la mayor transformación social, cultural, económica y medioambiental de la historia: la urbanización de la humanidad. Lógicamente, las autoridades locales y regionales son conscientes de su potencial económico y han ido logrando mayores cotas de recursos e influencia, hasta el punto que los procesos de descentralización - entendiendo por tales la transferencia de recursos, responsabilidades o autoridad pública desde los gobiernos centrales a los subestatales - constituyen una poderosa tendencia global. ${ }^{1}$

Cuando dejamos de lado las fronteras estatales y centramos esta mirada más profunda en Europa, una mirada que escape del nacionalismo metodológico y de la visión estatocéntrica, aparece una nueva realidad. Así, si se observa una fotografía por satélite de Europa, las fronteras estatales desaparecen y surgen ejes que articulan la geografía del continente: el mar y las costas, los grandes ríos, los macizos montañosos, etc. Si se toma esa misma fotografía nocturna, se ve que la población y la actividad económica están repartidas de forma muy desigual, brillando con intensidad las regiones más urbanas y ricas agrupadas en la denominada banana, que se extiende desde el norte de Italia, pasando por Suiza, suroeste de Alemania, Benelux y París, el gran Londres, hasta llegar al área de Liverpool y Manchester. Además de esta gigantesca conurbación europea, son distinguibles otros polos de desarrollo como las áreas de Roma o Atenas, un corredor mediterráneo sobre todo entre Barcelona y Marsella, un pequeño polo vasco-aquitano, la fachada atlántica del norte de Portugal y Galicia, etc. Esta fotografía también muestra los vacíos, las áreas despobladas y en declive: el «desierto» que rodea Madrid y que llega hasta las costas, del mismo modo que la Francia interior, casi vacía hasta que alcanza los bordes del hexágono (Burdeos, Toulouse, Montpellier, Marsella, Lyon, Estrasburgo, Metz).

Las luces brillando en la noche permiten observar la macrogeografía - como la denominan Thomas Farole et al.- subyacente, modelada por

1 Rodrigo Tavares (2016). Paradiplomacy. Cities and states as global players. New York, Oxford University Press. 
«las fuerzas de las aglomeraciones y las ventajas comparativas». Así, «dentro de la UE, existe una tendencia a concentrar la innovación y la actividad económica en el núcleo económico; dentro de los Estados la concentración se produce en las regiones núcleo (core regions); y dentro de las regiones la tendencia es a concentrarse en las áreas urbanas». Estos autores recuerdan un dato significativo: entre los 60 y los 80 , algunos investigadores consideraron que los procesos de convergencia que habían identificado «se producirían lenta pero seguramente en escalas territoriales cada vez más amplias». Sin embargo, «el cambio estructural en la economía mundial que se produjo en los 80 parece haber incrementado la importancia de la innovación para el crecimiento económico», lo que acarreaba poderosas «tendencias hacia la aglomeración en diversas escalas, y con ello, la importancia de la distribución espacial desigual de capacidades institucionales para innovar». ${ }^{2}$

De esta forma, los datos muestran que el proceso de convergencia en general se ha dado entre Estados, pero simultáneamente se ha agravado la polarización entre las distintas regiones de los países europeos. ${ }^{3}$ Además, las disparidades económicas intrarregionales (capital, ingresos, empleo, productividad laboral, PIB, nivel de vida), se suman a las que existen entre Estados y entre regiones. ${ }^{4}$

Siendo esto así, en contra de la idea habitual que ve a los países europeos como entidades discretas y relativamente homogéneas (cultural, económica y socialmente), Europa presenta una unidad profunda que a su vez se descompone, de forma muy sofisticada, en una compleja jerarquía de centros y periferias. Como es obvio, esta estructura tiene consecuencias de todo tipo: sociales, laborales, económicas, educativas, etc., pero lo curioso es que las áreas similares, - espacios centrales, zonas desindustrializadas, áreas con alto desempleo - rara vez coinciden con las fronteras estatales, sino que agrupan áreas genuinamente transfronterizas, esto es, europeas, porque siguen lógicas igualmente transnacionales. ${ }^{5}$

2 Thomas Farole, Andrés Rodríguez-Pose y Michael Storper (2011), «Cohesion policy in the European Union: growth, geography, institutions», Journal of Common Market Studies, Vol. 49, No. 5, 1089-1111.

3 Parlamento Europeo (2007). Regional disparities and cohesion: What strategies for the future. Policy Department structural and Cohesion Policies, IP/B/REGI/ IC/2006_201, 14/05/2007. Acceso: 21 de diciembre de 2018. [http://www.europarl.europa.eu/ hearings/20070625/regi/study_en.pdf]

${ }^{4}$ Stryjakiewicz, Tadeusz (2018), «Urban regeneration in Poland's non-core regions», European Planning Studies, Vol. 26, No. 2,316-341.

5 Dimitris Ballas, Danny Worling y Benjamin Hennig (2014). The social atlas of Europe. Bristol, Policy Press. 
En este contexto, no puede sorprender que se esté produciendo en los últimos tiempos una emergencia de actores no estatales, y la creciente politización de algunos de ellos. Si los Estados ofrecen una variada tipología: grandes potencias, potencias regionales, potencias medias, micro-estados, etc., con variables niveles de poder y ambición, lo mismo sucede con las regiones (y con las entidades locales).

De forma similar, Callanan y Tatham observan que no todos estos actores subestatales actúan de la misma forma, ya que algunos de ellos desempeñan roles de liderazgo gracias a sus capacidades y ambición política. Por ello, sugieren que - en cuanto actores - tiene más sentido agrupar las regiones fuertes (73 REGLEG) y las asociaciones fuertes de entidades locales entre sí - y simétricamente agrupar el resto de regiones con las entidades locales y sus asociaciones débiles de entidades locales-, antes que seguir ordenándolas según la división habitual entre regiones por un lado y entidades locales por otro. Estos autores también descomponen los objetivos de la movilización subestatal en financieros (búsqueda de fondos europeos, obtención de ventajas económicas) y regulatorios (participación en los procesos políticos de toma de decisiones). ${ }^{6}$

Ello conduce al debate de qué regiones, y en qué medida, son objetos o sujetos de las políticas de la Unión Europea, ${ }^{7}$ lo que remite a un debate aún más amplio sobre la condición de verdaderos sujetos políticos de estos actores en general. Desarrollando la clasificación de los actores subestatales fuertes, merecen una atención diferenciada las regiones fuertes con estatutos especiales, que normalmente suelen coincidir con las nacionalidades constitucionales.

Es muy relevante, dentro de una tendencia general que trata de desarrollar políticamente el nivel regional de los Estados europeos y de la Unión Europea ${ }^{8}$ que la Cámara de las Regiones del Consejo de Europa, en su sesión del 30 de octubre de 2013, adoptase un Informe sobre Regiones y Territorios con estatuto especial en Europa, elaborado por Bruno Marziano, y en el que se demostraba que los principios de la democracia regional encontraban los marcos más adecuados y convincentes en estas regiones con estatuto especial.

${ }^{6}$ Mark Callanan y Michael Tatham (2014), «Territorial interest representation in the European Union: actors, objectives and strategies», Journal of European Public Policy, Vol. 21, No. 2, 188-210.

7 Caitriona Carter y Romain Pasquier (2010), «The europeanization of regions as "spaces for politics": a research agenda», Regional and Federal Studies, Vol. 20, No. 3, 295-314.

${ }^{8}$ Declaración de Helsinki de 2002 sobre autogobierno regional; Marco de referencia del Consejo de Europa sobre democracia regional (2009). 
La adopción de este informe se acompañó de la Recomendación 346 (2013), en la que el Congreso de las Autoridades Locales y Regionales del Consejo de Europa se mostraba convencido de que:

$a$. much of the future of the European space, its future peaceful and prosperous development will depend on making greater progress in conflict prevention and resolution, which will require the political will to pursue peaceful political dialogue and to move forward on identifying and negotiating legal and constitutional solutions, to develop satisfactory models of decentralized democratic governance for regions with specific issues and identities;

$b$. the regional level of self-government remains an under-exploited structure for the political and economic development of European states and for responding to the legitimate democratic demands of their citizens;

c. special regional autonomy status can be an effective counterbalance to secessionist tendencies.

Y solicitaba, en consecuencia, que el Comité de Ministros:

$a$. invite member states to make greater use of the special status model, as a realistic option for a negotiated solution to regional territorial issues, including frozen conflicts;

$b$. involve the Congress, the Parliamentary Assembly and the Venice Commission in this work;

c. examine how special regional status can contribute to addressing the territorial issues faced by countries with which it is cooperating in the framework of the Council of Europe's policy towards neighbouring regions;

$d$. include, in the context of its political dialogue with the Congress, a transversal examination of the conditions for successful regional autonomy.

En realidad, este informe y su recomendación asociada, reconocen y aceptan que hay dos tipos de regiones. Por un lado, hay un tipo general de región, que agrupa a la gran mayoría de regiones europeas, y que se encuentra razonablemente bien integrado dentro del marco estatal y europeo actual. Pero, además, existen otras regiones que, debido a particulares necesidades derivadas de su historia, posición geográfica, cultura o características lingüísticas, demandan una respuesta distinta del Estado. Estas regiones, si bien son poco numerosas, constituyen a su vez una categoría particular, ya que existen en distintos países europeos. El informe señala que todos los Estados han terminado por reconocer que estas realidades precisan de un tratamiento diferencial y un estatuto especial. 
El interés del Consejo de Europa por estos estatutos especiales es antiguo $^{9}$, como lo es su convencimiento del potencial de esta vía para evitar la secesión y canalizar los conflictos territoriales y políticos de forma adecuada y pacífica. El Informe Marziano afirma en su punto 6 que el estatuto especial, cuando se establece en orden a acomodar grupos etnoculturales minoritarios, «se considera como la expresión más genuina de la autodeterminación interna de los pueblos (aunque el término apenas se emplea en los actos legales)».

El Informe señala que «todos los Estados compuestos, se llamen federales o regionales, se basan en algún grado de asimetría», lo que supone que «asimetría y diferenciación son innatos en cada forma de la división territorial del poder» (punto 8). El estatuto especial implica «la garantía legal de más poderes (legislativos, administrativos o financieros)» y normalmente también «formas privilegiadas de representación y negociación - a menudo mediante canales bilaterales con el Estado» (punto 9).

Dos años después, la Cámara de las Regiones del Consejo de Europa, en su sesión de octubre de 2015, adoptó una importante Resolución sobre «Las tendencias en la regionalización de los Estados miembros del Consejo de Europa», elaborada por Marie-Madeleine Mialot Muller. Esta resolución se acompañó de un estudio sobre la evolución de la regionalización en los países del Consejo de Europa. La conclusión fue descorazonadora: la regionalización de Europa apenas ha avanzado en la última década, con la única excepción de Bélgica, donde se ha reforzado el poder regional con una reforma que ha modificado el funcionamiento de la segunda cámara. Por el contrario, la tendencia general es hacia un reforzamiento del poder central del Estado. ${ }^{10}$

9 Pueden mencionarse la Recommendation 70 (1999) on local law/special status, basado en un estudio del Congreso que promueve la introducción o preservación de distintas formas de estatuto especial «con el objetivo de encontrar soluciones a los actuales conflictos en Europa»; también la Recomendación 1609 (2003) de la Asamblea Parlamentaria del Consejo de Europa sobre Positive experiences of autonomous regions as a source of inspiration for conflicto resolution in Europe. Igualmente, en 1999 varios miembros de la Asamblea Parlamentaria presentaron una «moción para la resolución de los conflictos étnicos en los Estados del Consejo de Europa» (Doc. 8425), en la que se destacaba la importancia del estatuto especial como un medio de resolución de conflictos; un año después la Comisión para la Democracia a través del Derecho (Comisión Venecia) enfatizó el potencial de los acuerdos a través de estatutos especiales para resolver conflictos en el General Legal Reference Framework to facilitate the settlement of ethno-political conflicts in Europe, adoptado en octubre de 2000 (CDL$\mathrm{INF}(2000) 16)$.

${ }^{10}$ Se observa una tendencia general contraria al poder regional. En Francia, por ejemplo, se ha reducido el número de las regiones de 22 a 13, combinando regiones existentes y transfiriendo departamentos de una región a otra. En Alemania e Italia ha surgido un debate similar, aunque de momento no se ha plasmado en reformas legales o políticas de calado. En 
El presente artículo tratará de comprender mejor estas tendencias contradictorias mediante un marco general de análisis que tenga en cuenta las dinámicas generales que generan o agudizan la condición periférica de los distintos actores en las diversas escalas. Por ello, primero se describirán algunas tendencias de periferialización para, a continuación, explorar las distintas respuestas que se están dando a dichas tendencias.

\section{Procesos de periferialización}

\section{Periferialización de Europa y procesos de integración}

Aunque su proceso de declive se había iniciado tiempo atrás, la devastación material de las dos guerras mundiales impidió cualquier intento de enmascarar el hecho obvio: Europa ya no era el centro del mundo. El centro económico mundial ya había pasado de Londres a Nueva York con la crisis de $1929,{ }^{11}$ y los acuerdos de Yalta y Postdam indicaban que la guerra contra los fascismos dejaba paso a la lucha por el centro político mundial entre los EEUU y la URSS.

Después de la Gran Guerra (1914-18), algunos intelectuales como el conde Coudenhove-Kalergi ya avisaron de la decadencia de Europa y la necesidad de crear una federación europea. ${ }^{12}$ Aristide Briand fue el primer estadista que señaló abiertamente el reto, la necesidad ineludible de unir los pueblos de Europa, si esta civilización quería dejar de autodestruirse y seguir siendo influyente en el mundo.

En realidad, todos los gobiernos europeos eran perfectamente conscientes de la necesidad de unir sus países, como probó sin duda la buena acogida, casi entusiasta, que tuvo el Memorándum de Briand en 1930, o las negociaciones que tuvieron al respecto Briand y Stresemann entre 1925 y $1932 .{ }^{13}$

España han aumentado las voces que piden el «cierre» del modelo autonómico e incluso, crecientemente, los sondeos indican un aumento considerable - si bien sigue siendo minoritario - de quienes piden la supresión de las autonomías; mientras, simultáneamente, otras voces piden iniciar una reforma constitucional que federalice el Estado y que aborde la cuestión de la plurinacionalidad del Estado (Francesco Merloni (ed), 2016, Regionalisation trends in European countries, 2007-2015: A study by members of the group of independent experts of the European Charter of Local Self-Government. Strasbourg, Congress of Local and Regional Authorities - Council of Europe ).

${ }^{11}$ Fernand Braudel (1985). La dinámica del capitalismo. México D.F., Fondo de Cultura Económica.

12 Richard Nikolaus Coudenhove-Kalergi (1923). Pan-Europa. Madrid, Editorial Encuentro.

${ }^{13}$ Igor Filibi (2014), «La Unión Europea veinte años después de Maastricht: hitos y retos», Cuadernos Europeos de Deusto, n. ${ }^{\circ}$ 50, 19-50. 
La necesidad de la escala europea para competir con los mercados norteamericano, británico y ruso, resultaba obvia en los círculos estatales del poder, a falta de concretar - lo que no era poca cosa-, el modelo concreto del proceso.

Es obvio que tanto el imperativo integrador, la necesidad irremisible de unir el continente, como los temores y angustias de su proceso de maduración, provenían de la posición crecientemente periférica de Europa (ver gráfico 1).

La debilidad de una Europa dividida, destruida por la guerra y con sus sistemas productivos a falta de una urgente modernización se agravaba al situarse en un contexto marcado por el surgimiento de dos potencias de una nueva clase, con mercados gigantes y recursos ilimitados. ${ }^{14}$ Otro factor de alarma era la creciente tensión entre tales potencias, con el riesgo de que la escalada militar incluyese las nuevas armas atómicas y el frente principal estuviese de nuevo, por tercera vez en tres décadas, en Europa.

Ante este panorama, los europeos rápidamente fueron conscientes - de forma aún más acusada que en 1918 - que los dilemas morales derivados de la guerra eran comunes a ambos bandos. Además, resultó igual de perturbador el hecho que, a la luz de la destrucción material y espiritual de las dos guerras, ningún bando europeo había verdaderamente vencido en el conflicto. Unas ideas sobre la libertad, los derechos y la democracia sí se habían impuesto a los fascismos, pero desde el punto de vista de los pueblos, de las personas que vivían en Europa, todos, colectivamente, habían sido gravemente dañados por el conflicto y la situación del conjunto era de extrema gravedad si la integración no comenzaba de forma urgente. ${ }^{15}$

Ahora bien, tal proceso sólo se activó cuando el proceso de declive de Europa era imparable y la periferialización del continente ya evidente. A pesar de las decenas de proyectos anteriores,${ }^{16}$ la integración europea sólo tuvo efectos políticos prácticos cuando los países europeos entendieron que

14 Jean Monnet constató en una conferencia en Bruselas en 1953: «En la mayor parte de los terrenos se constata una reducción del peso relativo de Europa en el mundo. He aquí un ejemplo: en 1913 Europa occidental, al oeste del Oder, representaba el 45\% de la producción industrial del mundo; en 1937 había caído al 34\%; en 1951 ya no es más del 26\%. Mientras que la producción del mundo se triplicaba, la de Europa occidental no llegaba a duplicarse. (...) La renta per cápita nacional, que en los Estados Unidos alcanza los 1.575 \$, es en los seis países citados [de la CECA] sólo de entre 250 y 500». Jean Monnet (2008), Los Estados Unidos de Europa han comenzado. Madrid, Instituto de Estudios Europeos y Ediciones Encuentro, 31-2.

15 Jean Monnet (1985). Memorias. Madrid, Siglo XXI.

16 Antonio Truyol (1999). La integración europea. Análisis histórico-jurídico con textos y documentos. Madrid, Tecnos. 
la centralidad europea había llegado a su fin, y sus gobiernos fueron capaces de trascender el modelo intergubernamental, aceptando el método funcionalista de pequeños pasos basado en compartir la soberanía. ${ }^{17}$

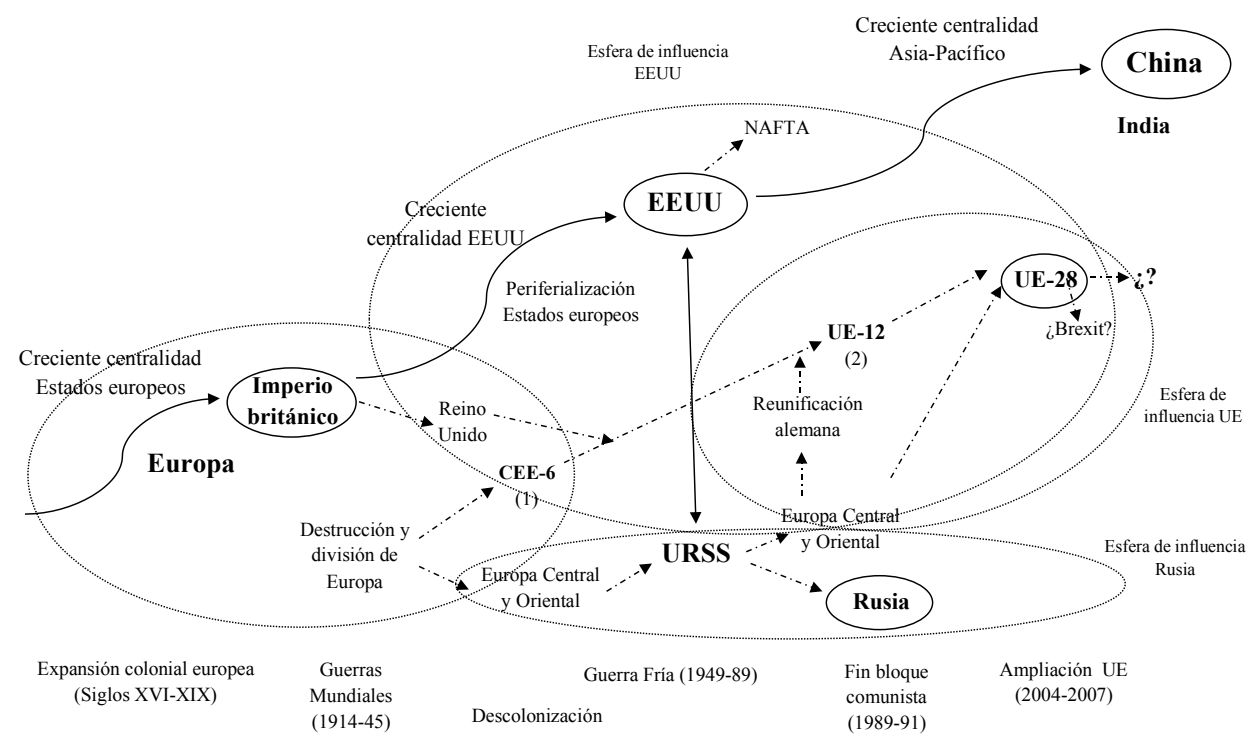

\section{Gráfico 1}

Proceso de periferialización de Europa

Notas: (1) Europa como actor comercial y económico;

(2) Europa crecientemente como actor político

Fuente: Igor Filibi (2019)

\section{Periferialización de los Estados e integración sub-regional}

Cuando se lee sobre los orígenes de la integración europea, entre los muchos factores y condicionantes de las decisiones de los gobiernos, hay uno que aparece constantemente: el miedo de todos los gobiernos a perder la centralidad de los acontecimientos. ${ }^{18}$ En medio de la marea de propuestas

${ }_{17}$ Francisco Aldecoa (2002). La integración europea. Análisis histórico-jurídico con textos y documentos. Vol. II: Génesis y desarrollo de la Unión Europea. Madrid, Tecnos.

18 Alan S. Milward (1984). The reconstruction of Western Europe 1945-51. Berkeley, University of California Press, 250-254. 
de alianzas, integraciones económicas y federaciones - que constantemente se negociaban desde el periodo de entreguerras entre países de Europa occidental, de Europa oriental y entre los nórdicos-, es un hecho recurrente que cada una de estas propuestas originaba en los participantes un cauteloso estudio sobre su viabilidad e impacto económico, tanto como causaba una inmediata preocupación acerca de esas mismas consecuencias económicas y geopolíticas en el resto de países. Los miedos a la creación de mercados cerrados o protegidos con aranceles y otras barreras, inmediatamente amenazaba la propia viabilidad de terceros países, que se ponían manos a la acción con propuestas alternativas de unión con otros países igualmente excluidos.

Por las más diversas razones - de índole doméstica, subregional o geopolítica mundial-, todos los Estados temían los riesgos de ciertas uniones tanto como deseaban otras. Alemania, dividida en cuatro zonas de ocupación, temía al futuro como el que más. Italia negoció sin descanso una integración de su mercado con Francia, para acceder a un mercado importante y para asegurarse las vitales materias primas. La propia Francia se debatió sin descanso entre distintas opciones de integrar los mercados europeos, entre ellas una unión arancelaria con los tres países del Benelux y Reino Unido, como forma de incorporar más tarde a Alemania. Mientras esta opción era paralizada una y otra vez por el gobierno británico, Francia avanzaba en las negociaciones para crear un solo mercado con Italia, y solo cuando los británicos claramente se negaron a avanzar, los franceses se lanzaron a liderar el proceso europeo con el apoyo norteamericano.

Si las potencias dudaban, calculaban y temían las implicaciones de estos procesos - incluidos EEUU y la URSS, que constantemente estaban informados y trataban de influir en los acontecimientos europeos-, no pueden sorprender los temores y angustias de los Estados más pequeños. Suecia, Finlandia, Dinamarca, Holanda o Noruega, por poner algunos ejemplos, participaban de aquella confusión que marcaría el rumbo de Europa y tal vez del mundo. Si Dinamarca apostaba por la integración con los países de Europa occidental (Benelux, Francia y Reino Unido), Holanda no quería dar un paso mientras los británicos no iniciasen el proceso; y Finlandia sólo aspiraba a que aquellos movimientos no rompiesen los frágiles equilibrios que le separaban de la Unión Soviética y garantizaban su estatalidad.

Las numerosas propuestas de integración económica y política debatidas entre 1929 y 1960 , dan cuenta de la necesidad imperiosa de abordar la integración, tanto como las dudas sobre la forma de llevarla a cabo. Sin entrar en los detalles, que no vienen aquí al caso, sí puede señalarse el punto central que queremos defender aquí - la angustia a la marginación, a la pe- 
riferialización - en el momento decisivo de 1950. Tras numerosos avatares, Francia lidera el proceso con la propuesta de Robert Schuman y Jean Monnet. Alemania entendió las bondades del plan, y los elevados costos que le supondría no aceptarlo, tanto en términos económicos como de marginación internacional. Italia se encontraba en una situación similar. Los países del Benelux, si bien Holanda intentó hasta el final la participación británica debido a su dependencia comercial, lograron lo que venían deseando desde un tiempo atrás: asegurarse un amplio mercado e integrar (lo que significaba sujetar) a Alemania.

Los británicos, que apostaban únicamente por una integración de los mercados, rechazaron desde el primer momento la idea de poner en común las soberanías y la finalidad federal del proceso.${ }^{19}$ No aceptaron nunca este principio, y se opusieron con todas su fuerzas. Cuando comprendieron que los otros seis gobiernos seguirían adelante, incluso sin ellos, comenzaron a trabajar en una vía alternativa de asegurarse amplios mercados, y crearon la Asociación Europea de Libre Comercio (EFTA). De nuevo el miedo a quedar marginado impulsaba otro proceso de integración. Y cuando éste fracasó, tuvieron que aceptar la realidad y sumarse al proyecto al que tanto se habían opuesto - aunque fuese para transformarlo desde dentro.

También la Unión Soviética temía la integración europea, y siempre que pudo la obstaculizó. En todo lo que dependía de Moscú, se evitó el éxito de la integración europea y occidental, tanto prohibiendo a sus países satélites sumarse al Plan Marshall, como a Finlandia unirse incluso a cualquier proceso de integración limitado a la región nórdica, por suave que éste fuese. Del mismo modo, estos países, una vez que vieron que la Europa de los Seis se convertía en realidad, impulsaron diversas iniciativas subregionales que culminarían con la creación del Consejo Nórdico en 1952.

Si el miedo a quedar en una posición periférica fue un factor decisivo en la construcción inicial de las Comunidades Europeas (así como en la creación de la EFTA o del Consejo Nórdico), en sentido contrario, el fin de la Guerra Fría constituyó una oportunidad que los europeos aprovecharon creando la unión Europea.

A comienzos de este siglo, el desplazamiento tectónico del centro de gravedad mundial hacia la región Asia-Pacífico reactivó el miedo de quedar marginados y parece haber impulsado una ambición renovada de constituirse en un actor internacional con capacidad de influencia, si bien

19 Arnold J. Zurcher (1958). The struggle to unite Europe, 1940-1958. New York, New York University Press. 
con grandes problemas derivados del contexto marcado por la gran crisis mundial (2007-2017). La ambición exterior rusa, el despliegue diplomático y militar chino, sumada a las crecientes dudas sobre el compromiso norteamericano en Europa, y la salida del Reino Unido de la Unión Europea, son factores que ayudan a despertar estos miedos geoeconómicos y geopolíticos sobre la posición crecientemente periférica de Europa, y parecen impulsar la integración en áreas hasta ahora vedadas, como política exterior y defensa. ${ }^{20}$

A su vez, dentro de la propia Europa, existen centros y periferias. El área que une el norte de Italia con el Gran Londres a través del sur de Alemania, Gran Paris y parte del Benelux, mantiene aún su centralidad económica. Sin embargo, el centro político no ha dejado de desplazarse hacia el este desde el fin de la Guerra Fría, primero con la reunificación alemana (1990), y posteriormente con la gran ampliación al centro y este de Europa (2004-2007).

París está a 500 kilómetros de Bonn, pero a mil de Berlín. En la Europa de los Seis, París era el centro geográfico y político de la Comunidad. En la Unión Europea ampliada de 28 las cosas han cambiado. En el eje norte-sur, entre Helsinki y Lisboa hay $4400 \mathrm{~km}$; con centro geográfico en Frankfurt. Si se toma el eje Edimburgo-Atenas, la distancia es de $3800 \mathrm{~km}$, y el centro estaría situado en Praga.

Si esto sucede con París, es fácil imaginarse la percepción de creciente distancia con los centros geográficos, económicos y políticos, que tienen capitales como las ya mencionadas Helsinki, Lisboa y Atenas, pero también Madrid, Roma o Bucarest.

Además de las cuestiones geográficas, las relaciones de poder y los equilibrios políticos han variado también. Alemania, tras su reunificación, superó ampliamente en población a los otros tres grandes Estados (Reino Unido, Francia e Italia). Fue sólo cuestión de tiempo que se rompiese el pacto no escrito de paridad total entre Alemania y Francia, como se vio en el Tratado de Lisboa, que concedió más parlamentarios a Alemania en función de su población, además de incluir la dimensión de población para activar el bloqueo de una decisión. Esto ha concedido (o reconocido) a Alemania más peso que a ningún otro país en la Unión.

Este aumento del peso alemán ha ido acompañado de una pérdida clara de influencia francesa, y también de Italia debido a sus permanentes convulsiones políticas. Esto dejaba al Reino Unido como el contrapeso político -y geopolítico debido a su potencia militar- de Alemania. Sin embargo,

${ }^{20}$ Francisco Aldecoa denomina a estos dos últimos factores como elementos federalizadores externos. Francisco Aldecoa (2017), «El futuro de Europa como proyecto político: hacia la federación europea», Revista de Derecho de la Unión Europea, n. ${ }^{\circ}$ 32, 13-17. 
la salida del Reino Unido (Brexit) rompería este esquema y causaría una reconfiguración profunda del mapa del poder en la Unión Europea.

Algunos analistas auguraban un aumento del peso relativo de los dos Estados medios-grandes (España y Polonia). No obstante, si diversos Estados ya habían comenzado a agruparse en sistemas de cooperación sub-regionales (nórdicos, bálticos, Visegràd, ibéricos), como una forma de paliar su situación periférica y escasa influencia en la UE, el Brexit quizás potencie esta tendencia. En cualquier caso, aunque se remonta al comienzo de la integración (Benelux), el sub-regionalismo constituye un importante factor de dinamismo de la integración europea en los últimos tiempos.

Del mismo modo que el descentramiento mundial de Europa fue un factor decisivo de su integración, dentro de la Unión también existen periferias, que se van reconfigurando mediante descentramientos progresivos. Estos procesos, que van empujando hacia posiciones más marginales a ciertos Estados, incentivan el surgimiento o intensificación de procesos de cooperación e incluso integración sub-regional, como estrategia para ganar influencia en las decisiones de la Unión.

\section{Periferialización de las regiones}

\subsection{Periferialización dentro del Estado}

Durante la construcción de los Estados modernos y los mercados nacionales, y a lo largo de los procesos de homogeneización cultural y nacionalización de sus sociedades, algunos territorios se incrustaban en el centro de tales procesos, impulsándolos y controlándolos, mientras que otros territorios quedaban fuera de ese núcleo estatal y nacional, en posiciones más o menos periféricas.

Sigue siendo interesante, y revelador, observar los ejes de fractura (cleavages) que identificó Stein Rokkan en la paulatina constitución de las sociedades europeas. ${ }^{21} \mathrm{La}$ secular tensión entre el mundo rural y el emergente mundo urbano, con la apuesta clara de las burguesías nacionales por las ciudades como centros de comando del proceso, iban vertebrando el Estado y sus relaciones de poder. La industrialización se convirtió en otro eje de división dentro del Estado, con polos de desarrollo por un lado, y regiones enteras que quedaban excluidas de la principal fuente de riqueza, por otro lado. A su vez, los procesos de construcción nacional, con su centralización del poder del Estado y la creación de nue-

${ }^{21}$ Peter Flora (2007). State formation, nation-building, and mass politics in Europe. The theory of Stein Rokkan. Oxford, Oxford University Press. 
vas políticas estatales (educación, ejército nacional, cierta regulación del mercado y del trabajo, primeras políticas sociales, etc.), iban generando una emergente solidaridad e identidad nacionales. Pero también surgían resistencias, que en determinados territorios podían llegar a ser muy importantes, e incluso desembocar en insurrecciones y conflictos armados.

La consecuencia de estos procesos complejos e interrelacionados fue la generación de centros y periferias dentro de los territorios del Estado. La piedra angular de la construcción de los Estados, el principio monárquico, se había modificado profundamente, y ello supuso la reordenación completa del territorio. La nueva política territorial tendió a ser - con escasas excepciones, como EEUU y algún otro Estado federal inspirado en la Revolución Americana-, muy centralizadora, inspirada en el modelo jacobino que se impuso en la Revolución Francesa. La distribución del territorio se modificó sustancialmente, y en ocasiones de forma radical y premeditada para romper los vínculos con las regiones históricas. El caso de Francia es probablemente el más extremo, ya que cambió todas las fronteras interiores del territorio estatal (ahora nacional), y los nombres de los nuevos departamentos no tuvieron ninguna relación con las antiguas regiones medievales - los denominados cuerpos intermedios.

El mismo proceso de reordenación de las provincias se produjo en España, y en otros países. El Estado moderno usó la política territorial como un potente instrumento al servicio de la construcción nacional, junto con la educación y la historia, y el ejército nacional como un potente mecanismo de socialización nacionalista. La experiencia de la guerra fue otro crisol de pueblos para reforzar el sentimiento nacional en la población. La solidaridad de las trincheras fue convertida por el Estado en legitimidad, ayudada por las incipientes políticas sociales. Es una historia conocida, como también son conocidos los efectos territoriales de la consolidación del mercado nacional.

En definitiva, el proceso de construcción del Estado moderno tuvo efectos territoriales desiguales. Unas regiones formaron parte del núcleo alrededor del cual se vertebró el Estado, mientras que otras regiones quedaban en las fronteras, a menudo disputadas por otros Estados y sometidas a los vaivenes de las guerras y las bodas reales. Algunas regiones compartían cultura y lengua con la elite que lideraba la construcción nacional, mientras que otras regiones tenían culturas y lenguas distintas, a menudo con instituciones y tradiciones jurídicas diferentes. La revolución industrial marcó también el territorio, potenciando unas regiones que adoptaron antes y mejor las nuevas técnicas, y dejando a otras regiones centradas en actividades de menor valor añadido. Y todas estas diferencias y contrastes se expresaban ideológicamente: emergía un mundo liberal, liderado por las ciudades 
más grandes y con tradición comercial, que se oponía a un mundo agrario, más conservador y que temía los cambios. ${ }^{22}$

\subsection{Periferialización dentro de la UE}

Con el relanzamiento de la integración, sobre todo a partir de la creación de la Unión Europea (UE) y el desarrollo de la Unión Económica y Monetaria (UEM), diversas regiones comenzaron a evaluar seriamente su posición dentro del emergente marco político europeo.

Este diagnóstico respecto a la propia posición dentro del marco de la UE se vio completamente reconfigurado por el proceso de ampliación hacia el centro y este de Europa. En todas las anteriores ampliaciones se habían producido correcciones y ajustes, pero la escala numérica y geográfica de esta ampliación implicó un completo desplazamiento del centro de gravedad de la UE hacia el este ${ }^{23}$, que incluía una mejor conexión física de las regiones centrales y una creciente concentración en ellas de la propiedad y control de la industria. ${ }^{24}$

La magnitud de la transformación generó dos tipos de procesos de periferialización regional en la UE ampliada:

a) Regiones que internamente ya eran periféricas (o no estaban bien posicionadas), veían cómo el desplazamiento del centro de la UE hacia el este les alejaba también de los centros de decisión e influencia. Esto suponía la creación de regiones doblemente periféricas (en sus Estados y en la UE). El País Vasco-francés es un buen ejemplo de esto. Esta región, que ya era periférica dentro de Francia, reaccionó al proceso de descentramiento de su Estado articulando un potente movimiento social transversal para obtener un de-

22 Para el caso de Francia, Ver: Edward W. Fox, (1971). History in geographic perspective. The other France. New York, Norton. Esta tesis de las dos Francias fue enriquecida y completada con el análisis de Fernand Braudel (1992). Civilization and capitalism (15th - 18th century), Vol. III: The perspective of the world. Berkeley, University of California Press, 342. En esta obra, Braudel afirma la existencia de una Francia interior (la «Otra Francia» de Fox) y dos Francias fronterizas y dinámicas. Orientadas respectivamente hacia el mar y hacia el continente europeo.

${ }^{23}$ Este desplazamiento geográfico fue acompañado de la creciente hegemonía de la Alemania reunificada, como comenzó a ser evidente al observar cómo los marcos institucionales de la UE replicaban modelos institucionales alemanes (Charlie Jeffery, (2007) «Transnational networking as institutional export: the case of Bavaria», en: Le Gloannec, Anne-Marie (ed.). Non-state actors in international relations: The case of Germany. Manchester, Manchester University Press, 130-144).

${ }^{24}$ Danson (2009), «New regions and regionalization through clusters: City-regions and new problems for the periphery», International Journal of Public Sector Management, Vol. 22 , No. 3, 260-271. 
partamento propio, considerado imprescindible para articular una estrategia de desarrollo regional adaptada a sus circunstancias. ${ }^{25}$ Esta activación regional se produjo exactamente a la vez que se firmaba el Tratado de Maastricht, indicando claramente la conexión entre ambos procesos. Fruto de esta misma tendencia, el propio Estado decidió acometer una completa transformación de su política regional e incluso de la estructura territorial del Estado. ${ }^{26}$

También hay casos de regiones de los países del este que ven que durante la transición a la economía de mercado, y pese a las políticas regionales y de cohesión de la UE, no mejoran sus resultados económicos. ${ }^{27}$

b) Regiones que no eran periféricas dentro de sus Estados, pero pasaban a serlo de forma creciente - o su posicionamiento empeoraba sustancialmente - en el conjunto de la UE ampliada. Una conclusión obvia de este proceso, que las regiones afectadas aprendieron pronto, era que estar bien situadas en su Estado, o incluso ser la región-capital del mismo, ya no aseguraba una posición central dentro de la UE. Algunas regiones importantes de los países nórdicos podrían ser un buen ejemplo de esta categoría.

\section{Respuestas a los procesos de periferialización}

\section{Federalismo}

El impacto de la Primera Guerra Mundial creó las condiciones para que surgiesen las primeras propuestas verdaderamente federales para Europa, como Paneuropa (1923) o las de los federalistas personalistas de los años 1930 en torno a la revista L'Ordre Nouveau, destacando Alexandre Marc, Dennis de Rougemont o Henri Brugmans. Estos autores serían decisivos en la diseminación de las ideas federalistas y en el impulso de la acción política, destacando su papel en el Congreso de Europa de La Haya. ${ }^{28}$

25 Igor Ahedo (2006). El viaje de la identidad y el nacionalismo vasco en Iparralde (1789-2005). Vitoria-Gasteiz, Servicio Central de Publicaciones del Gobierno Vasco.

${ }^{26}$ Romain Pasquier (2009), «The Europeanisation of French regions», French Politics, Vol. 7, No. 2, 123-144.

27 Tadeusz Stryjakiewicz, Robert Kudlak, Przemyslaw Ciesiólka, Bartlomiej Kolsut y Pawel Motek (2018), «Urban regeneration in Poland's non-core regions», European Planning Studies, Vol. 26, No. 2, 316-341.

28 José Luis Valverde, «Introducción al pensamiento y acción de Alexandre Marc», en: Alexandre Marc. El porvenir de Europa y otros ensayos. Madrid, Centro de Estudios Constitucionales y BOE, 1994. 
La crisis económica y el ascenso de los fascismos cortaron aquel debate necesario, que siguió produciéndose, pese a todo, incluso durante la Segunda Guerra Mundial. Manifiestos como el de Ventotene (1943) o el de las Resistencias Europeas (1944), abogaban claramente por una Europa federal. También en la Europa oriental surgieron propuestas de integración regional que pudiesen ser preludio y parte de una integración europea más amplia, como la fracasada negociación entre Polonia y Hungría en 1943. ${ }^{29}$

El Congreso de Europa (1948) pareció zanjar la cuestión del método al renunciar a la revolución y apostar por un sistema de «pequeños pasos». También pareció quedar claro el objetivo final - la Federación europea - y las características supranacionales de la integración. El éxito de la primera Comunidad Europea, del carbón y del acero, en 1951, y la creación de dos comunidades más en los Tratados de Roma de 1957, parecían despejar el camino. El inicio de la Guerra Fría limitó los avances de la integración a la Europa occidental.

El federalismo europeo se plasma en un proyecto político viable sobre la base de un pacto constitucional europeo de posguerra - que incluye las reformas constitucionales de los países fundadores, y constituye un desarrollo de los sistemas democráticos de sus países participantes-, y es la expresión de tres compromisos. En primer lugar, un consenso político entre distintas familias (demócrata-cristianos, socialistas y liberales) sobre un modelo de economía de mercado y bienestar social (modelo social europeo), inspirado en unos valores humanistas; en segundo lugar, un compromiso entre el principio supranacional federal y las soberanías estatales, que se plasmó en el sistema institucional comunitario y en el método funcionalista de los «pequeños pasos»; y, en tercer lugar, el propio desarrollo del proceso de integración ha promovido la evolución de los debates y las posiciones iniciales, en el sentido de un acercamiento progresivo de ambos polos ideológicos - el de la soberanía estatal y el del federalismo supranacional.

Así, por un lado, hasta los más firmes defensores de la soberanía reconocen hoy que el Estado, en solitario, no puede afrontar con éxito la mayor parte de los grandes desafíos del siglo XXI. También aceptan que algunas parcelas concretas de soberanía se gestionan de forma más eficiente en común. Si bien el punto hasta el cual esto es deseable constituye un aspecto importante de la discusión y, en general, quienes defienden estas posiciones rechazan la idea de una federación europea completa.

${ }^{29}$ Lane, Thomas (2007), «Integrating East Central Europe. Polish and Czechoslovak plans and the opposition of the great powers, 1939-1945», Central and Eastern European Review, Vol. 1, 1-32. 
Por otro lado, de forma simétrica, el federalismo europeo ha evolucionado desde planteamientos fundamentalmente ideológicos - casi una fe europeísta - hacia propuestas más pragmáticas, que reconocen que los Estados deben seguir desempeñando un papel relevante o, por ejemplo, que la Unión no tiene por qué ser más eficiente en todos los casos y políticas. Aquí quedaría en el centro del debate qué áreas deben ser decididas en el nivel europeo y bajo qué mecanismo (unanimidad, tipos de mayoría).

En este contexto, puede pergeñarse el surgimiento de un nuevo federalismo europeo, más pragmático y flexible, y que ha evolucionado desde las fórmulas iniciales inspiradas en modelos clásicos de federación (los Estados Unidos de Europa), hasta los desarrollos más recientes que trascienden este esquema y desarrollan el concepto de proceso federal. Este nuevo clima federalista, más abierto, casi experimental, por tener que innovar y desarrollar sus conceptos casi sobre la marcha, ofrece propuestas creativas que cuestionan los modelos federales clásicos como referentes para la UE.

En los últimos años han surgido varias aproximaciones novedosas al federalismo europeo, entre las cuales cabe destacar la del federalismo intergubernamental ${ }^{30} \mathrm{o}$ la propuesta del federalismo experimental, inspirada en las ideas de Sabel y Zeitlin, que propone Matiaz Nahtigal. En relación con esta última, tal y como se ha visto anteriormente, ya antes del estallido de la crisis de 2008, la mayor parte de los expertos y muchos gobernantes consideraban que era necesario completar la integración europea. Había numerosas voces abogando por establecer una unión bancaria completamente desarrollada, una unión fiscal y algún tipo de unión política basada en una gobernanza económica común. Hay quien ve en estas propuestas un gran paralelismo con la época del New Deal y el desarrollo del constitucionalismo norteamericano. Nahtigal argumenta que esta trayectoria, aunque sea posiblemente más prometedora que la insostenible situación actual, no es la única senda posible para el desarrollo de la UE:

Hasta la fecha el discurso de la integración europea se ha centrado en reforzar el poder de las instituciones supranacionales a la vez que limitaba el margen de maniobra de los Estados y sus regiones para enfrentar sus crisis. La premisa de de tal enfoque era que este es el mejor modo de preservar la unidad del mercado común y la unidad del modelo socio-económico. Desde un punto de vista conceptual,

${ }^{30}$ Maurice Croisat y Jean-Louis Quermonne (1999). L'Europe et le fédéralisme. Contribution à l'emergence d'un fédéralisme intergouvernemental. París, Montchrestien. 
no se apreció lo suficiente que no existe una mejor manera, natural, neutral, de economía de mercado a la que deban aspirar todos los Estados miembros y sus regiones. Desde un punto de vista histórico, se ignoró que el periodo más exitoso de la integración europea se dio en las primeras dos décadas, caracterizado no solo por el pleno empleo, crecimiento de salarios, sistemas desarrollados de bienestar social y sistemas financieros relativamente estables, sino también por las mayores variedades institucionales del capitalismo europeo. Mayor autonomía en las elecciones de políticas, instrumentos y articulación de estrategias de desarrollo, se ajustaron a las necesidades y potenciales de las diversas comunidades locales a lo largo de la UE, junto con innovaciones institucionales, fueron las características más importantes de este periodo. ${ }^{31}$

Por supuesto, es imposible replicar las condiciones excepcionales de la posguerra, pero sí se plantea que habría que reforzar la capacidad de gobernanza en todos los niveles de la UE. Para Sabel y Zeitlin, la Unión Europea debería convertirse en una máquina de aprendizaje de la diversidad, permitiendo que distintos actores - con distintas circunstancias afronten problemas parecidos con fórmulas variadas. A pesar de que raramente las fórmulas pueden exportarse a otros lugares, los otros actores sí pueden aprender y ser inspirados por los distintos diseños de políticas. Así, «en vez de construir una integración europea centralizada» - siguiendo los postulados del federalismo clásico más que los del federalismo cooperativo-, se trataría de favorecer la experimentación, lo que fortalecería y ampliaría las opciones políticas, a la vez que permitiría que los actores tomasen las riendas de sus propias estrategias de desarrollo. ${ }^{32}$

Estas propuestas federalistas, a las que podría añadirse la diseñada por el Parlamento Europeo en sus resoluciones del 16 de febrero de 2017, plantean el debate federal europeo en términos nuevos. ${ }^{33}$ Lentamente, con dificultades de todo tipo, el debate federal va abandonando los perfiles del federalismo estatocéntrico y se van esbozando los contornos de un federalismo, adaptado a la complejidad de la Europa y el mundo actual, que entra en terreno desconocido; un terreno en el que los federalistas integrales acer-

31 Matjaz Nahtigal (2016), «From classical toward experimental federalism: Different pathways for a more inclusive and balanced European Union», Lex Localis - Journal of Local Self-Government, Vol. 14, No. 3, 523-537.

32 Nahtigal, experimental federalism.

33 Filibi, Igor (2018), «La Europa necesaria es federal y social: el debate sobre el futuro de Europa y la propuesta del Parlamento Europeo», en: Eurobasque (ed.). Nuevas narrativas para Europa. ¿Qué Europa reconstruir tras 60 años de los Tratados de Roma?, Madrid, Dykinson. 223-239. 
taron con su planteamiento superador del marco estatal, pero cuyas líneas concretas aún deben ser desarrolladas a partir de complejos consensos políticos y aprovechando imprevisibles estructuras de oportunidad.

\section{Sub-regionalismo}

La creación de grupos sub-regionales parece ser una tendencia general a nivel mundial después del fin de la Guerra Fría. Desde finales de la década de 1980, emergió un cinturón de nuevos grupos sub-regionales en Europa, que se extiende desde la zona de Barents en el lejano Norte, hasta el mar Negro en el sur. Estos nuevos marcos de cooperación constituyen una nueva e importante dimensión de las relaciones internacionales europeas. ${ }^{34}$ A mediados de la década de 1990 se desarrollaron los planes de la ampliación hacia el este tanto en la OTAN como en la UE, y creció el interés por estos grupos subregionales. Debido al miedo de crear nuevas divisiones de Europa entre los países que se integrarían en la UE y los que no, así como debido a que las relaciones de estos subgrupos fueron madurando, las grandes organizaciones como la UE, OTAN, OSCE o la UEO comenzaron a mostrar un creciente interés por la promoción de estas cooperaciones sub-regionales y la cooperación con ellas, así como desarrollar en términos prácticos una especialización o división del trabajo entre ellas. ${ }^{35}$

Se crearon grupos sub-regionales amplios como el Consejo Barents Euro Ártico, el Consejo de Estados del Mar Báltico, la Iniciativa Centro Europea o la Cooperación Económica del Mar Negro, que jugaron un importante papel en la gestión del fin de la Guerra Fría y en la inicial reorganización del espacio europeo. Los grupos sub-regionales más pequeños y más homogéneos - como el grupo Visegrado y el Acuerdo de Libre Comercio de Europa Central - permitieron, a su vez, que países de Europa Central y Oriental que no pudieron cooperar durante la Guerra Fría se acercasen entre sí y reforzasen su posición en sus relaciones con Rusia y con Europa occidental. ${ }^{36}$

También constituye una innovación relevante la creación del Consejo Británico-Irlandés como consecuencia de los acuerdos de Viernes Santo de 1998. Esta nueva generación de iniciativas sub-regionales tiene como característica que están surgiendo en las periferias europeas (centro y este de

${ }^{34}$ Cottey, Andrew (2000), «Europe's new subregionalism», Journal of Strategic Studies, Vol. 23, No. 2, 23-47.

${ }^{35}$ Cottey, Europe's new subregionalism, 4.

${ }^{36}$ Cottey, Europe's new subregionalism, 253, 243-244. 
Europa, islas británicas y, aún sin formalización institucional pero con clara voluntad política, en la península ibérica). Las nuevas iniciativas se suman a las ya existentes, algunas de las cuales eran ya antiguas, como el Benelux y el Consejo Nórdico, ambas formadas justo después de la Segunda Guerra Mundial. No obstante, ambas siguen evolucionando e intensificando su cooperación.

Un elemento común a todas ellas es que, a pesar de su proliferación y de su éxito relativo, casi todos los países europeos ven las relaciones y la cooperación sub-regional como un complemento de su integración en la Unión Europea, más que como una alternativa a la misma. ${ }^{37}$ En este sentido, están desempeñando importantes funciones de coordinación política, agregación de intereses para elaborar propuestas y facilitar la obtención de las minorías de bloqueo en el Consejo, cuando algún Estado ve amenazados intereses importantes. ${ }^{38}$

Dentro del dinamismo de este tipo de integración sub-regional - aún poco estudiado ${ }^{39}-$, que suele ser intergubernamental (sin implicar soberanía compartida como en la UE), destaca que se ha abierto a la participación plena de regiones, sobre todo de aquellas que tienen conciencia nacional. Así, en el consejo Nórdico participan las Islas Faroe, Aaland y Groenlandia, y en el Consejo Británico-Irlandés participan, junto a los gobiernos británico e irlandés, todas las naciones de las Islas Británicas excepto Inglaterra - Irlanda del Norte, Escocia y Gales- , así como las Islas del canal y de Man. ${ }^{40}$

También están surgiendo contactos estructurados e iniciativas de cooperación entre procesos sub-regionales, como por ejemplo entre los Bálticos y los Nórdicos, ${ }^{41} \mathrm{o}$ de éstos con el grupo de Visegràd. Teniendo en cuenta que la definición geográfica y el significado de las sub-regiones europeas no han dejado de variar a lo largo del tiempo, ${ }^{42}$ quizás en el futuro estas relaciones puedan transformarse en nuevas espacialidades sub-regionales más amplias, al menos en relación con ciertas políticas o temas de interés común.

37 Cottey, Europe's new subregionalism, 251

38 Gron, Caroline Howard; Nedergaard, Peter y Wivel, Anders (eds) (2015). The Nordic countries and the European Union. Still the other European community? Abingdon, Routledge, 243.

39 Cottey, Andrew (2000), «Europe's new subregionalism», Journal of Strategic Studies, Vol. 23, No. 2, 23-47.

40 Vernon Bogdanor (1999), «The British-Irish Council and devolution», Government and Opposition, Vol. 34, No. 3, 287-298.

${ }^{41}$ Marc Cogen (2015). An introduction to European intergovernmental organizations. Farnham, Ashgate.

42 Diana Mishkova y Balázs Trencsényi (eds.) (2017). European regions and boundaries: A conceptual history. New York, Berghahn. 


\section{Regionalismo y regionalización}

La cuestión regional es antigua, pero de nuevo se introduce en la agenda política. Algunos aspectos de su problemática surgieron durante los procesos de construcción y consolidación de los Estados modernos, que fueron suprimiendo el poder e influencia de los denominados cuerpos intermedios. Otros aspectos, más vinculados con aspectos administrativos y económicos, emergieron a mediados del siglo Xx. Por último, la construcción europea, en particular durante el proceso de culminación del mercado interior y la creación de la Unión Europea, crearon condiciones para que las regiones, de nuevo, volviesen a entrar con fuerza en la agenda política, esta vez no sólo estatal sino también europea.

Se trata, por tanto, de una cuestión compleja, que se ha prolongado en el tiempo y que abarca diferentes dimensiones (económica, cultural, administrativa, política, e incluso geopolítica). Michael Keating identifica tres tipos principales de respuestas que se han dado a lo largo del tiempo ante la cuestión regional: regionalización, regionalismo y autonomía. ${ }^{43}$

\section{a) Regionalización}

El propio Estado, ante el desarrollo desigual de los distintos territorios, elabora una planificación territorial como política de Estado. Se trata de descomponer el territorio estatal en unidades más pequeñas que permitan una mejor gestión de los recursos y una mejor implementación de las políticas. Así, el centro estatal crea una serie de regiones en base a criterios funcionales del propio Estado, y de eficiencia. Estas regiones son simplemente administrativas para desconcentrar algunas decisiones y procedimientos, y en ocasiones permiten la implementación más particularizada de algunas políticas generales. El centro regionaliza el territorio, sin consultar a estos nuevos entes administrativos y sin transferirles ningún poder efectivo, más allá de cierto margen interpretativo de las normas estatales. ${ }^{44}$ Otra cuestión capital es la financiación, ya que en este modelo las regiones apenas tienen margen de decisión sobre la asignación del gasto, limitándose a ser generalmente oficinas de pago de las políticas es-

${ }^{43}$ Michael Keating (1998). The new regionalism in Western Europe. Territorial restructuring and political change. Aldershot, Edward Elgar.

44 Por ser centrales en estos procesos los factores funcionales, también se ha denominado a esta forma de política territorial como regionalismo funcional, si bien esta denominación puede incitar a la confusión con el regionalismo que, como se verá a continuación, es muy distinto a la regionalización. 
tatales (mantenimiento de instalaciones, sueldos de funcionarios, tramitación y pago de subvenciones, etc.).

Un ejemplo de cómo opera esta lógica regional puede verse en la última reorganización territorial de Francia, donde el gobierno ha decidido reformar completamente el número y tamaño de las regiones francesas con el objetivo de dotarlas de masa crítica para poder competir con las regiones de otros Estados europeos y, al mismo tiempo, lograr algunas economías de escala y sinergias que permitiesen un ahorro en el gasto público. ${ }^{45}$

Durante el transcurso de la reciente crisis económica mundial, se ha observado que uno de los aspectos claves de las políticas regionales de los Estados europeos, la estrategia basada en impulsar algunas regiones líderes (economic champions), siempre de carácter urbano, vinculadas con centros de desarrollo, etc., no sólo no conseguía arrastrar hacia el crecimiento a las regiones consideradas más «atrasadas», sino que acentuaba su situación periférica. Ello ha llevado a plantearse qué políticas son adecuadas para las regiones que ni son urbanas ni son centrales o polos de desarrollo. ${ }^{46}$

\section{b) Regionalismo}

En Europa puede observarse que las políticas de construcción de los Estados nacionales han tenido resultados desiguales. En muchos casos, la identidad nacional del Estado ha sido aceptada por la inmensa mayoría de la población y constituyen parte del sentido común de sus ciudadanos que, en general, se identifican con su nación y su Estado. En otros lugares, algunas regiones históricas, si bien pueden compartir buena parte del proyecto nacionalista estatal, no aceptan que ello sea a costa de abandonar sus viejas instituciones de autogobierno, su identidad y cultura, y a veces incluso su propio derecho.

En estos casos, han surgido movimientos que reclaman su derecho a ser reconocidos como sujetos políticos distintos, con un elevado nivel de autogobierno que les permita mantener sus costumbres e instituciones, así como su estrategia de desarrollo propio. Aquí, la región se convierte en un proyecto político que busca la aceptación del Estado y, en los casos en los que el Estado está muy centralizado, ello implica - en alguna medida - la transformación del propio Estado, para acoger esta diferencia dentro de su territorio.

45 Pasquier (2009), The Europeanisation of French regions; Javier Tajadura, (2017) «Las reformas del modelo de descentralización territorial de Francia: la necesaria simplificación del “milhojas" territorial», Revista Vasca de Administración Pública, n. ${ }^{\circ}$ 108, 181-223.

46 Danson (2009), New regions and regionalization through clusters. 
En otros casos, no muy numerosos pero políticamente bastante significativos, como resultado de procesos muy complejos - sociales, económicos, culturales y políticos - el territorio no solo define una identidad regional potente - normalmente en base a instituciones existentes, $\mathrm{y}$ un discurso regionalista que reclama el respeto y mantenimiento de su cultura, etc.sino que se articula un verdadero proyecto distinto al del Estado. Se trata de construir otro centro, social y cultural, que devenga político y económico, para el mejor desarrollo de su región. En este caso, en el extremo del regionalismo - a menudo mezclado socialmente con él-, surge el nacionalismo periférico o alternativo. A veces, este nacionalismo refleja miméticamente al del Estado ${ }^{47}$ y exige su derecho a construir su propio Estado, invocando el derecho de autodeterminación y la secesión. ${ }^{48}$ Otras veces, el movimiento nacionalista propone algún tipo de acuerdo para compartir el Estado, normalmente con un reconocimiento de su realidad nacional y cultural distintiva. ${ }^{49}$

El punto en común de las distintas variedades del regionalismo, incluyendo la versión nacionalista, radica en que estos movimientos construyen e invocan ser un centro desde el cual identificar sus problemas, definir sus prioridades y establecer su propia agenda política. Se trata de que el territorio propio se convierta en marco de referencia: social, cultural, económico, educativo, laboral, político.

Ser centro, y actuar en coherencia con esa categoría, implica convertirse en sujeto político, un sujeto no reducible a otros centros (sean estatales o de otro tipo, por ejemplo la UE). A diferencia de las regiones creadas por el Estado, donde el centro decisor era siempre el centro estatal, el regionalismo exige el reconocimiento de su condición de sujeto por parte del Estado, y en consecuencia la transformación de las políticas estatales (esto es, respetando el ámbito regional de decisión). Es importante observar que ser sujeto político no implica necesariamente tener que convertirse en Estado. La estatalidad es la forma ideológica extrema de un sujeto político. Pero no es la única.

47 A menudo suele olvidarse, incluso en la literatura académica, que el nacionalismo periférico es una reacción al nacionalismo estatal, aunque éste se disfrace con el adjetivo "cívico» o el sustantivo «patriotismo», y se envuelva en un manto de «sentido común», lo que se ha denominado nacionalismo banal. Ver: Igor Filibi (2007). La Unión como marco de resolución de los problemas etnonacionales europeos: un enfoque comparado. Leioa, Servicio Editorial de la Universidad del País Vasco, Michael Billig (1995). Banal nationalism. Los Angeles, SAGE.

${ }^{48}$ Francisco Letamendia (2000). Game of mirrors: Centre-periphery national conflicts. Aldershot, Ashgate.

49 Daniel L. Seiler (1989), «Peripheral nationalism between pluralism and monism», International political Science Review, Vol. 10, No. 3, 191-207. 
En verdad, ser sujeto significa que el punto de vista de éste no puede evitarse u obviarse. Significa que la región debe poder examinar su situación libremente, pensarse a sí misma, conocer por sí misma los problemas, poder definirlos en sus términos y de acuerdo con sus intereses y prioridades. Ser sujeto significa que nadie puede hacer esto por ti, que la población de la región, de forma democrática, discute las alternativas y establece sus preferencias, y luego batallará políticamente para defender sus intereses y su estrategia de desarrollo propio.

Ser un sujeto político $-\mathrm{y}$ haber pensado, debatido y decidido la propia agenda y posiciones políticas -, no implica que éstas deban llevarse a cabo siempre y necesariamente, como planteaba la soberanía clásica en el nivel del Estado; aunque, simétricamente, si las posiciones propias nunca son aceptadas, no podríamos estar ante un caso de un sujeto político, sería una burda mascarada. Del mismo modo que los Estados europeos actuales fijan sus posiciones nacionales y luego abordan la negociación en las instituciones comunitarias, también las regiones pueden fijar las suyas y luego participar de estas negociaciones en el marco del Estado, o de la propia UE, respetando e implementando las decisiones finales según los procedimientos establecidos.

En el marco de la integración europea, con el desarrollo y evolución de la Unión, se produce una cierta convergencia entre los conceptos fundamentales del regionalismo y del nacionalismo periférico. En realidad, la realidad fáctica de la integración, con su redefinición de la soberanía, ha ido convergiendo hacia un concepto de autonomía fuerte (para distinguirlo de un concepto de autonomía débil que suele ser habitual en los procesos de descentralización estatal, que se verá a continuación).

En general, los movimientos regionalistas y nacionalistas suelen surgir, como respuesta social y política a la percepción de encontrarse en una situación periférica dentro del Estado (política, cultural, económica), o por entender que los intereses propios no están suficientemente bien defendidos por el centro y sus políticas estatales (Cuadro 1). Esta situación periférica no puede limitarse a lo geográfico, ni a lo económico. Puede suceder que la situación de periferia provenga de una discrepancia radical en las preferencias políticas de la mayoría regional, que pueden ser completamente distintas de las mayoritarias en el conjunto del Estado (como sucede en Escocia). 


\section{Cuadro 1}

Ejes de referencia del posicionamiento regional en sus marcos políticos (estatal y europeo)

\begin{tabular}{|l|l|l|l|}
\hline $\begin{array}{l}\text { Centralidad-periferialidad } \\
\text { Fusión-diferenciación de intereses re- } \\
\text { gionales respecto a los intereses de las } \\
\text { elites centrales }\end{array}$ & $\begin{array}{l}\text { Capacidad política } \\
\text { de defender los intereses privativos regionales } \\
\text { (elevado nivel competencial, financiación su- } \\
\text { ficiente, acceso a los foros de decisión estata- } \\
\text { les y europeos) }\end{array}$ \\
\cline { 2 - 5 } & $\begin{array}{l}\text { Capacidad } \\
\text { alta }\end{array}$ & $\begin{array}{l}\text { Capacidad } \\
\text { media }\end{array}$ & $\begin{array}{l}\text { Capacidad } \\
\text { baja }\end{array}$ \\
\hline $\begin{array}{l}\text { Intereses incrustados en el sistema polí- } \\
\text { tico, fusión de la mayoría política regio- } \\
\text { nal con la mayoría del Estado }\end{array}$ & CENTRO & & \\
\hline $\begin{array}{l}\text { Intereses regionales claros, agenda pro- } \\
\text { pia, mayoría política regional }\end{array}$ & & & \\
\hline $\begin{array}{l}\text { Intereses regionales difusos, sin agenda } \\
\text { propia }\end{array}$ & & & \\
\hline $\begin{array}{l}\text { Nota: esta clasificación se podría descomponer en distintas variables económicas, polí- } \\
\text { ticas, institucionales, por territorios, sectores, etc. }\end{array}$ & & \\
Fuente: Igor Filibi (2019) & & & \\
\hline
\end{tabular}

\section{c) Autonomía regional}

Según Michael Keating, ${ }^{50}$ esta sería la respuesta del Estado a las demandas de un movimiento regionalista (o nacionalista), con el fin de acomodar sus reclamaciones dentro del marco estatal, aumentar la legitimidad del Estado y de la nación mayoritaria en el territorio, y — desde el punto de vista de la habitual realpolitik - para evitar el riesgo de secesión del territorio. Se trataría, siguiendo los conceptos de Albert Hirschman ${ }^{51}$, de optar por dar voz al territorio (Voice), antes que tener que enfrentarse a un proceso que reclame la salida (Exit) del Estado.

Los estados descentralizados políticamente - sean Estados asimétricos, regionales o autonómicos-, presentan una tensión común entre el centro y las unidades políticas subestatales, con sus correspondientes tendencias centrípetas y centrífugas. Ahora bien, a menudo el centro suele tender a desarrollar modelos de autonomía débil, la mínima necesaria para evitar la secesión,

50 Michael Keating, The new regionalism in Western Europe.

${ }^{51}$ Albert O. Hirschman (1970). Exit, Voice, and Loyalty: Responses to decline in firms, organizations and states. Cambridge, Harvard University Press. 
siempre arrastrados por la inercia centralista inherente al Estado moderno. En realidad, suele tratarse de modelos de descentralización producidos como consecuencia del miedo a la secesión, más que debido a un genuino reconocimiento de la pluralidad política. Normalmente el centro y la mayoría política del Estado suele considerar la autonomía dentro de una pirámide normativa en la que el centro, llegado el caso, podría invocar su mayoría para alterar las reglas del juego, lo que es percibido por la región política - lógicamentecomo una amenaza existencial a su condición de sujeto distinto.

Frente a esa tendencia, las regiones más conscientes de su identidad diferenciada y las naciones periféricas, desarrollan su concepción de sujetos políticos y exigen al Estado su transformación para que sea posible una noción de autonomía fuerte, que esté asegurada de forma estructural, sin tener que depender del color del gobierno y sin que su posición constitucional se vea amenazada ante las mayorías estatales, que escapan al control de la región/nación minoritaria.

Otro aspecto de gran importancia en los casos donde existen autonomías en Estados descentralizados políticamente, radica en que estas regiones poseen sus propios parlamentos, gobierno, etc. Eso implica que estas regiones son gobernadas en base a sus propias mayorías políticas. Cuando la mayoría regional es muy distinta de la mayoría estatal, de forma sistemática, expresando valores o prioridades políticas muy diferentes, ello puede llegar a crear una grave crisis de legitimidad en el Estado. En particular cuando la región política tiene una fuerte conciencia nacional, y ese proyecto nacionalista está respaldado de forma continua por una mayoría política, aunque tal mayoría no sea suficiente para iniciar un proceso de secesión pactado, es obvio que se produce un choque de legitimidades entre dos mayorías políticas distintas.

En el marco europeo, no hay duda que la integración política ha afectado de forma importante al ejercicio y al reparto competencial de las regiones con autonomía política. Tras el auge de las regiones en el contexto de la crisis industrial de los 80 y el relanzamiento europeo que creó la Unión en 1993, donde se llegaron a proponer ideas sobre la Europa de las regiones y de los pueblos, ${ }^{52}$ pronto se vio que el proyecto de integración no iba en aquella dirección. ${ }^{53}$

52 Susana Borrás-Alomar; Thomas Christiansen y Andrés Rodríguez-Pose (1994), «Towards a "Europe of the Regions"? Visions and reality from a critical perspective», Regional politics and Policy, Vol. 4, No. 2, 1-27; José Luis de Castro Ruano (1994). La emergente participación política de las regions en el proceso de construcción europea. Oñati, IVAP; Anwen Elias (2008), «Introduction: Whatever happened to the Europe of the Regions? Revisiting the regional dimension of European politics», Regional \& Federal Studies, Vol. 18, No. 5, 483-492.

53 Eve Hepburn (2008), «The rise and fall of a "Europe of the Regions"», Regional \& Federal Studies, Vol. 18, No. 5, 537-555. 
Después de una fase de cierta frustración, en la que, no obstante, la actividad regional no cesó en el marco europeo ${ }^{54}$, surgen nuevas ideas - como las Naciones Autónomas Europeas sugeridas por Iñigo Bullain ${ }^{55}$ - y las regiones políticas más dinámicas comienzan a reorganizarse y articular formulaciones que persiguen mejorar su inserción dentro de la gobernanza de la Unión; en este sentido pueden destacarse el documento del Gobierno Vasco con su Visión del futuro de Europa ${ }^{56}$ o las Contribuciones de las RLEG a la Task Force sobre Subsidiariedad y proporcionalidad. ${ }^{57}$

\section{Reflexiones finales}

Europa es la escala adecuada para muchos de los principales problemas y retos de la actualidad, por eso la Unión es necesaria. Es obvio que no es perfecta, y se pueden encontrar documentos oficiales con una importante carga de autocrítica, pero las críticas deben estar orientadas a su reforma. Europa no se puede permitir la destrucción de la Unión. Es la única opción de contener el declive de Europa y poder reactivarla.

Las fotografías de satélite, los sondeos regulares de Eurostat o el Atlas social de Europa, nos muestran a un continente unido en múltiples aspectos, pese a su diversidad. Por ello es necesario ver y pensar Europa en términos propiamente europeos. Ello no significa obviar ni eliminar el agregado estatal, pero este nivel político, tan importante por tantos motivos (identidad, cultura, solidaridad, etc.), no puede monopolizar la visión de la realidad, porque en ocasiones la enmascara y genera efectos estadísticos que no permiten comprender correctamente los problemas y las tendencias generales europeas.

También es necesario ver y pensar las regiones en términos europeos y en términos propiamente regionales. En línea con las recomendaciones internacionales ya mencionadas anteriormente, es necesario unir ambas dimensiones. Si bien es cierto que en los últimos años se han producido algunos avances en la cuestión regional, son claramente insuficientes. El federalismo europeo debe incorporar la complejidad del nivel regional en sus articulaciones y propuestas, para lo cual no servirá una Federación clásica

${ }^{54}$ Mark Callanan y Michael Tatham (2014), «Territorial interest representation in the European Union: actors, objectives and strategies», Journal of European Public Policy, Vol. 21, No. 2, 188-210.

55 Iñigo Bullain, «Naciones autónomas europeas», Deia, 24 de septiembre de 2018 [https://www .deia.eus/2018/09/24/opinion/tribuna-abierta/naciones-autonomas-europeas] Acceso: 24 de septiembre de 2018.

$56 \mathrm{http}: / / \mathrm{www} . e u s k a d i . e u s / c o n t e n i d o s /$ informacion/accion_exterior_hemeroteca/es_def/ adjuntos/Vision_del_Futuro_de_Europa.pdf

$57 \mathrm{http}: / / \mathrm{www}$.euskadi.eus/pdf/rleg-task-force.pdf 
y simétrica, sino algo que, por definición, deberá ser original, asimétrico y complejo.$^{58}$ Es tanto una cuestión de eficacia política, de legitimidad democrática y cercanía con la ciudadanía, y de efectividad en el desarrollo de los distintos tipos de regiones, pues la Unión debe reconocer las importantes diferencias entre las regiones.

En particular, un tipo muy específico de regiones merecen atención, las regiones y nacionalidades constitucionales que poseen una conciencia nacional mayoritaria, un sistema de partidos propio y mayorías políticas sistemáticamente distintas de las que gobiernan su Estado. Aquí nos encontramos ante un caso grave de desajuste democrático, que es preciso abordar y resolver cuanto antes. La movilización muy activa de un grupo reducido de regiones en este sentido demuestra dos cosas: que es una reclamación muy importante para estas regiones/nacionalidades, y su reducido número deja patente que se trata de un problema manejable, que podría solucionarse mediante un esfuerzo razonable de interpretación de los tratados si hubiese voluntad política suficiente.

Básicamente pueden darse dos tipos de escenarios. Por un lado, en los casos en los que una mayoría política defienda el carácter nacional del territorio, su identidad privativa y diferencial, y sus preferencias o intereses distintos de los mayoritarios dentro del Estado, pero no alcance mayoría suficiente para llevar adelante una propuesta democrática de secesión; en estos casos debe encontrarse un mecanismo de acomodación adecuado, que reconozca el carácter político de estos sujetos en el ámbito europeo y permitiendo su participación directa en los procesos de toma de decisiones de la UE bajo fórmulas acordadas entre los Estados afectados, las instituciones comunitarias y los Estados miembros. Esto también obliga a ciertos cambios en los Estados afectados, debiendo reacomodar sus acuerdos constitucionales a la realidad evolutiva de la integración europea. ${ }^{59}$

58 Para una magnífica visión general de los retos de la complejidad en la construcción de una democracia europea, Ver: Daniel Innerarity (2017). La democracia en Europa. Madrid, galaxia gutemberg.

59 Aquí resultan de interés propuestas como la de la eventual participación en las convenciones europeas de reforma de los tratados - quizás con voz pero sin voto o alguna fórmula que permita a la nacionalidad participar plenamente del proceso político e incorporar su visión única y sus propuestas al debate europeo, lo que acrecentaría de forma importante la legitimidad de la UE en tales territorios-; o la de que las nacionalidades constitucionales y las regiones políticas puedan - de acuerdo con procedimientos pactados con su Estado y las instituciones de la UE - descomponer el voto del Estado en el Consejo de la UE en aquellas competencias exclusivas de mayor importancia estratégica para la región. Ver: Eurobasque (2018). Aportaciones al debate sobre el futuro de Europa: Hacia una Europa federal y social. [http://70aniversario.eurobasque.eus/textos-de-reflexion/aportaciones-al-debate-sobreel-futuro-de-europa-hacia-una-europa-federal-y-social/] Acceso: 18 de septiembre de 2018. 
Por otro lado, cuando una mayoría social y política amplia reclame su estatalidad propia de forma sostenida en el tiempo, parece un imperativo democrático atender tal petición y acordar el mecanismo que haga posible que la voluntad popular se exprese y se lleve a efecto el resultado. En estos casos, la Unión Europea debería garantizar la limpieza del proceso y servir de garantía última a todos los ciudadanos afectados de que todos sus derechos serán respetados y cumplidos al margen del resultado final del proceso.

En la actualidad, la UE parece haber apostado por no facilitar la creación de nuevos Estados en el territorio de la Unión. En el difícil contexto que atraviesa el proceso de integración, podría llegar a entenderse que la Unión no quiera aumentar la división política del continente. Sin embargo, el cierre de la opción Exit debería ir acompañada de un desarrollo mucho más profundo de la opción Voice que, de momento, no se está produciendo. ${ }^{60}$

También, allí donde se están produciendo, siguiendo la estela del Consejo Nórdico y del Consejo Británico-Irlandés, las regiones políticas -y sobre todo las nacionalidades constitucionales - deben ser igualmente asociadas a las subregiones europeas que existen o puedan crearse en el futuro. Y la Unión Europea debería encontrar mecanismos que permitan asociar a estas realidades transnacionales europeas, al igual que las euro-regiones transfronterizas, a los procesos de la gobernanza de la UE.

Estos parecen ser algunos de los elementos más dinámicos de la integración europea, y la Unión debería tratar de asociar las energías desplegadas en estos campos al proceso de integración.

Por último, cuando se analizaban los procesos de periferialización, se mencionaba el impacto del miedo en el inicio o consolidación de diversos procesos de integración o movilización regional. El miedo puede ser un factor de la integración europea, pero no basta. Para avanzar de forma decidida en la integración política es necesaria la esperanza y la ilusión.

Hace no tanto tiempo surgieron proyectos que ilusionaron a una buena parte de la ciudadanía europea: se habló de crear una Unión Europea política, de una Europa de las regiones, de ciudadanía europea, de fondos de cohesión, de una constitución, de una carta de derechos de la Unión. Había diversos proyectos políticos que ilusionaban a distintos sectores de la población. Es necesario reconstruir aquel debate, en términos renovados, para

${ }^{60}$ En este sentido, resulta sorprendente la escasa atención que le dedica a la incorporación de las regiones al proceso político de la UE tanto la Comisión en sus documentos de reflexión sobre el futuro de Europa como, aún más llamativo, el Parlamento Europeo en sus resoluciones del 16 de febrero de 2017 que, por lo demás, son magníficas por su ambición política. 
impulsar de nuevo el proyecto político europeo; pero no puede realizarse de forma técnica, fría, entre expertos y elites políticas y económicas. Es necesario abrir las puertas a la participación de todo el que quiera aportar: movimientos sociales, jóvenes, regiones, territorios transfronterizos - verdaderas islas europeas, y ejemplo de las «solidaridades de hecho» de las que hablaba Schuman-, ciudades, etc. Sólo si se abre a una participación efectiva, el proyecto europeo estará verdaderamente adaptado a las necesidades, valores e intereses de la ciudadanía; y sólo así podrá ser apoyado de forma amplia y mayoritaria.

\section{Sobre el autor}

Igor Filibi es Doctor en Ciencias políticas y sociología por la Universidad del País Vasco (UPV/EHU), Diploma en Derecho Constitucional y Ciencia Política (Madrid, Centro de Estudios Constitucionales), Diploma en integración europea y Unión Europea, licenciado en ciencias políticas y en sociología política. Actualmente es profesor investigador de Relaciones Internacionales en la UPV/EHU. También imparte clases de integración europea en el University Studies Abroad Consortium (USAC). Ha impartido cursos de doctorado en el Instituto Internacional de Sociología Jurídica de Oñati y en la Universidad Autónoma de Baja California (México). Ha realizado estancias de investigación en el Centro de Estudios Avanzados (CEA, Universidad Nacional de Córdoba, Argentina) y en el Instituto de Estudios Internacionales (IDEI, Lima, Pontificia Universidad Católica del Perú). Sus líneas de investigación principales son la integración europea, los conflictos nacionalistas y el diseño e innovación en metodologías activas de enseñanza-aprendizaje.

\section{About the Author}

Igor Filibi is a PhD in Political Science and Sociology at the University of the Basque Country (UPV/EHU), Diploma in Constitutional Law and Political Science (Madrid, Center of Constitutional Studies), Diploma in European integration and European Union, BA in Political Science, BA in Political Sociology. Senior researcher of International Relations at the University of the Basque Country. He teaches European integration at University Studies Abroad Consortium (USAC). He has given Doctorate courses at the International Institute of the Sociology of Law (Oñati) and at the Universidad Autónoma de Baja California (México). Research stances 
at the Centro de Estudios Avanzados (CEA, Universidad Nacional de Córdoba, Argentina) and at the Instituto de Estudios Internacionales (IDEI, Lima, Pontificia Universidad Católica del Perú). His main research topics are Europan integration, nationalist conflicts and innovation in teachinglearning active methodologies. 


\section{Derechos de autor}

Los derechos de autor (para la distribución, comunicación pública, reproducción e inclusión en bases de datos de indexación y repositorios institucionales) de esta publicación (Cuadernos Europeos de Deusto, CED) pertenecen a la editorial Universidad de Deusto. El acceso al contenido digital de cualquier número de Cuadernos Europeos de Deusto es gratuito inmediatamente después de su publicación. Los trabajos podrán leerse, descargarse, copiar y difundir en cualquier medio sin fines comerciales y según lo previsto por la ley; sin la previa autorización de la Editorial (Universidad de Deusto) o el autor. Así mismo, los trabajos editados en CED pueden ser publicados con posterioridad en otros medios o revistas, siempre que el autor indique con claridad y en la primera nota a pie de página que el trabajo se publicó por primera vez en CED, con indicación del número, año, páginas y DOI (si procede). Cualquier otro uso de su contenido en cualquier medio o formato, ahora conocido o desarrollado en el futuro, requiere el permiso previo por escrito del titular de los derechos de autor.

\section{Copyright}

Copyright (for distribution, public communication, reproduction and inclusion in indexation databases and institutional repositories) of this publication (Cuadernos Europeos de Deusto, CED) belongs to the publisher University of Deusto. Access to the digital content of any Issue of Cuadernos Europeos de Deusto is free upon its publication. The content can be read, downloaded, copied, and distributed freely in any medium only for non-commercial purposes and in accordance with any applicable copyright legislation, without prior permission from the copyright holder (University of Deusto) or the author. Thus, the content of CED can be subsequently published in other media or journals, as long as the author clearly indicates in the first footnote that the work was published in CED for the first time, indicating the Issue number, year, pages, and DOI (if applicable). Any other use of its content in any medium or format, now known or developed in the future, requires prior written permission of the copyright holder. 